\title{
Karakteristik Iklim Mikro Dan Produksi Jagung Manis Pada Beberapa Sistem Tanam
}

\section{Characteristics of the Microclimate and Production Sweet Corn in Various Types of Cropping System}

\author{
Risa Wentasari, dan Rizka Novi Sesanti ${ }^{1}$ \\ ${ }^{1}$ Dosen Jurusan Budidaya Tanaman Pangan, Politeknik Negeri Lampung \\ Jl. Soekarno Hatta No 10 Rajabasa Bandar Lampung \\ Email : wenta_risa@yahoo.com
}

\begin{abstract}
The purpose of this study was to determine the characteristics of the micro-climate (temperature, humidity, and light intensity) and the production of sweet corn on a sigle row, doble row, twin row, and Twin seed planting system. This study was conducted in an experimental garden of Politeknik Negeri Lampung, Hajimena South Lampung, in JulySeptember, 2015. This study is based on randomized block design with one factor cropping system consists of 4 treatment ie : Sigle Row (SR) $(20 \mathrm{~cm} \times 75 \mathrm{~cm})$, Doble Row ( DR ) $(20 \mathrm{~cm} x$ $20 \mathrm{~cm} \times 80 \mathrm{~cm})$, Twin Row (TR) $(20 \mathrm{~cm} \times 10 \mathrm{~cm} \times 80 \mathrm{~cm})$, and Twin Seed (TS) with plant Spacing (40cm $\times 75 \mathrm{~cm} 2$ seed in one planting hole). Parameter observations of this study consisted of (1) micro-climate (temperature $\left({ }^{\circ} \mathrm{C}\right)$, relative humidity $(\mathrm{RH} \%)$ and Interception of Light (\%)) and (2)production (corn length $(\mathrm{cm})$, corn diameter $(\mathrm{m})$ ) and Corn weights (grams). The data were analyzed using the $F$ test at $1 \%$ and $5 \%$ level and than followed by test BNT. The conclusion of this study were (1) The characteristics of the microclimate : a) There is a noticeable difference in the temperature of the top of the current crop of 4 mst and at 9 mst there is a significant difference in the temperature of the bottom, where SR has a different temperature involves the other b) All systems planting has a relative humidity (\%) were not significantly different, and c) there is a difference light interception (\%) during the day when 4 mst, where the twins seed has a light interception is different from other treatments and there is a difference light interception during 9 mst where sigle row has a different light interception to other treatments. (2) The production of sweet corn on the treatment $S R, D R, T R$ and TS were not significantly different and has a weight of corn (SR = 354.8 grams, $D R=316.5$ grams, 328.5 grams $T R$ and $T S=325.4$ grams) same with description bonanza varieties (270-300 grams).
\end{abstract}

Keywords : Cropping Systems, Micro Climate, Production

Diterima: 19 Januari 2016, disetujui 30 Maret 2016

\section{PENDAHULUAN}

Cuaca atau iklim merupakan suatu faktor yang mempengaruhi pertumbuhan dan perkembangan tanaman. Untuk mengetahui efektifitas dari suatu sistem tanam maka perlu dilakukan pengkajian tentang iklim mikro, dimana iklim mikro yang kondusif akan memberikan lingkungan tumbuh yang baik bagi tumbuhan.

Iklim mikro merupakan iklim dilapisan udara dekat permukaan bumi dengan ketinggian \pm 2 meter, dimana pada daerah ini gerak udara lebih kecil karena permukaan bumi kasar dan perbedaan suhu yang besar. Keadaan tanaman dapat mengakibatkan perlawanan iklim yang besar dalam ruang yang sempit. Iklim mikro meliputi suhu, kelembaban dan cahaya. 

Pengaturan pola tanam bertujuan untuk menciptakan iklim mikro yang sesuai untuk pertumbuhan tanaman. Sistem tanam pada tanaman akan berpengaruh pada kerapatan populasi tanaman. Populasi tanaman menyebabkan perebutan kebutuhan hidup antar individu, baik ruang antau sumberdaya lain. Sehingga tercipta iklim yang khas pada satu populasi tanaman yang sering disebut iklim mikro.

Peningkatan produktifitas jagung terus dilakukan salah satunya penerapan dengan cara pengaturan jarak tanam. Teknologi ini digunakan untuk meningkatkan populasi yang optimal persatuan waktu. Hasil penelitian Sesanti RN dkk, 2013 mengenai sistem tanam jagung manis Dua Baris (DB) dengan jarak tanam $80 \mathrm{~cm} \times 20 \mathrm{~cm} \times 20 \mathrm{~cm}$ dan satu baris $20 \mathrm{~cm} \times 75 \mathrm{~cm}$ menunjukkan bahwa nilai rata-rata bobot tongkol dengan kelobot pada pola tanam SB sangat tinggi (642 g), sedangkan nilai rata-rata bobot tongkol dengan kelobot pada pola tanam DB rendah yaitu 319 g. namun demikian nilai rata-rata bobot tongkol tanpa kelobot pada pola tanam SB dan DB tidak berbeda yaitu 274,50 g dan 236,75 g.namun demikian, dari hasil tersebut diketahui bahwa budidaya jagung manis dengan pola tanam DB dapat meningkatkan hasil panen akibat penambahan jumlah populasi tanaman jagung manis per satuan luas.

Sistem tanam jajar legowo merupakan salah satu sistem tanam modifikasi dari sistem tanam monokultur dengan cara beberapa baris tanam diselingi dengan baris kosong dimana jarak tanam pada baris pinggir setengah dari jarak tanam baris tengah, sehingga terjadi peningkatan populasi per satuan luas. Pada tanaman jagung jajar legowo lebih ditujukan untuk :Meningkatkan penerimaan intensitas cahaya matahari pada daun dan diharapkan hasil asimilat meningkat sehingga pengisian biji dapat optimal. Memudahkan pemeliharaan tanaman, terutama penyiangan gulma baik secara manual maupun dengan herbisida, pemupukan, serta pemberian air (Balit Seral Litbang Deptan, 2013).

Penelitian ini bertujuan untuk mengetahui karakteristik iklim mikro (suhu, kelembaban, dan intensitas cahaya) dan produksi jagung manis pada sistem tanam sigle row, doble row, twin row, dan Twin seed.

\section{METODE}

Penelitian ini dilakukan di kebun percobaan Politeknik Negeri Lampung, Hajimena Lampung Selatan, pada bulan Juli - September 2015; Alat yang digunakan dalam penelitian ini : Alat budidaya secara umum (cangkul, kored, sprayer, ember, dll), Tube solary meter, termometer bola basah dan bola kering, timbangan analitik, meteran, jangka sorong. Bahan : Benih Jagung manis, Pupuk (Urea, SP36, KCl), Pestisida, Herbisida. Penelitian ini disusun berdasarkan Rancangan Acak Kelompok dengan satu faktor sistem tanam terdiri dari 4 perlakuan yaitu : Sigle Row (SR) Jarak Tanam $20 \mathrm{~cm}$ x $75 \mathrm{~cm}$, Doble Row (DR) Jarak Tanam $20 \mathrm{~cm}$ x $20 \mathrm{~cm}$ x $80 \mathrm{~cm}$, Twin Row (TR) $20 \mathrm{~cm}$ x $10 \mathrm{~cm}$ x $80 \mathrm{~cm}$, dan Twin Seed (TS) Jarak Tanam 40cm x $75 \mathrm{~cm} 2$ benih perlubang tanam.

\section{Tahapan Penelitian}

Persiapan Lahan. Pengolahan lahan dengan cara dibajak dan digaru dengan menggunakan hand traktor dan kemudian dilakukan membutan plot percobaan dengan ukuran 5 x 2 m sebanyak 12 plot percobaan.

Penanaman. Penanaman dilakukan dengan cara membuat lubang tanam dengan kedalaman $\pm 5 \mathrm{~cm}$, selanjutnya dilakukan penanaman sesuai dengan jarak tanam sesuai dengan perlakuan Sigle Row (SR), Doble Row (DR) dan Twin Row (TR) dilakukan penanaman 1 benih/lubang, dan Untuk Twin Seed (TS) dilakukan 2 benih/lubang.

Pemeliharaan. Pemeliharaan tanaman meliputi kegiatan penyulaman, Penyiangan, Pengairan, Pemupukan, pengendalian hama dan penyakit, pemupukan dengan dosis acuan yang digunakan $300 \mathrm{~kg}$ Urea/Ha, $100 \mathrm{~kg} \mathrm{SP36/Ha} \mathrm{dan} 100 \mathrm{~kg} \mathrm{KCl/ha.} \mathrm{Pemupukan} \mathrm{dilakukan} 3$ kali yaitu : Pemupukan I, dilakukan 7 
hari Setelah Tanam (HST) terdiri dari Urea 1/3 dosis, SP36, dan KCl, Pemupukan II, dilakukan 28-30 HST pemberian pupuk Urea 1/3 dosis, dan pemupukan III, 45-50 HST pemberian pupuk Urea 1/3 dosis.

Panen, dilakukan pada saat tanaman berumur 70-75 hari setelah tanam. Dengan kriteria kelobot sudah berubah warna agak kekuningan, tongkol jagung berisi penuh dan agak keras, serta warna rambut jagung yang sudah berwarna coklat kehitaman.

Pengamatan, parameter pengamatan terdiri dari :

1. Parameter Iklim Mikro meliputi :

a. Suhu udara $\left({ }^{\circ} \mathrm{C}\right)$, Pengukuran dilakukan dengan menggunakan termometer bola kering, pada 3 waktu pengamatan yaitu : 7.30, 12.30, dan 17.30, suhu rata-rata diperoleh dengan perhitungan berdasarkan Handoko (1994) sebagai berikut :

$$
\mathrm{T}(\text { rata }- \text { rata })=\frac{2 . \mathrm{T} 7.30+\mathrm{T} 12.30+\mathrm{T} 17.30}{4}
$$

b. Kelembaban (\%), Pengukuran dilakukan dengan mengunakan psikometer yang diamati 3 waktu pengamatan yaitu: 7.30, 12.30, dan 17.30. Untuk menentukan kelembaban nisbi dilakukan dengan menggunakan tabel psikomatrik, berdasarkan Tbk (suhu bola kering) dan $\Delta \mathrm{T}$ (selisih suhu bola kering dan bola basah). Kelembaban Rata-Rata (RH) dapat dihitung dengan persamaan berikut ini :

$$
\mathrm{RH}(\text { rata }- \text { rata })=\frac{\mathrm{RH} 7.30+\mathrm{RH} \mathrm{12.30+RH} \mathrm{17.3C}}{3}
$$

Untuk Suhu udara $\left({ }^{\circ} \mathrm{C}\right)$ dan Kelembaban (\%) dilakukan pengamatan bagian atas tanaman, tengah dan bawah.

c. Intersepsi Cahaya (\%), Pengukuran dilakukan dengan menggunakan Tube solarymeter, pada pukul $7.30,12.30$ dan 17.30

Untuk semua parameter iklim mikro 5 menit untuk setiap titik pengambilan data, dengan memindahkan alat dari petak ke petak.

Parameter Produksi

a. Diameter tongkol $(\mathrm{cm})$ dilakukan pada saat panen, dengan mengukur bagian tengah tongol tanaman sampel mengunakan jangka sorong.

b. Panjang tongkol $(\mathrm{cm})$ dilakukan pada saat panen dengan mengukur tongkol tanaman sampel dari pangkal tongkol sampai ujung tongkol menggunakan mistar pengukur.

c. Bobot Tongkol (gram), dilakukan pada saat panen dengan menimbang tongkol tanaman sampel.

Analisis data hasil penelitian dari tiap parameter pengamatan dilakukan analisis dengan menggunakan uji $\mathrm{F}$ pada taraf kesalahan $1 \%$ dan 5\%. Jika terdapat berbedaan nyata pada uji $\mathrm{F}$ maka dilakukan uji lanjut BNT.

\section{HASIL DAN PEMBAHASAN}

\section{Kondisi Iklim Makro}

Penelitian ini berlangsung pada bulan Juli sampai September 2015. Secara umum lokasi penelitian sedang berlangsung kemarau panjang, dengan kondisi hujan pada bulan juli 77,9 mm dengan 4 hari hujan, bulan Agustus 53,2 mm dengan 3 hari hujan dan Agustus 54.1 dengan 2 hari hujan. Suhu rata-rata harian bulan Juli $27^{\circ} \mathrm{C}$, Agustus $27,4^{\circ} \mathrm{C}$, dan September $26,8^{\circ} \mathrm{C}$.

Tanaman jagung memerlukan curah hujan optimum $100-125 \mathrm{~mm} / \mathrm{bulan}$ dan suhu $23^{\circ} \mathrm{C}-28^{\circ} \mathrm{C}$. Berdasarkan data curah hujan pada lokasi penelitian perlu dilakukan penyiraman. Akan tetapi panen pada 
musim kemarau lebih baik dibandingkan pada musim penghujan, karena berpengaruh terhadap semakin cepatnya pemasakan biji. (Rukmana R. 1997).

\section{Karakteristik Iklim Mikro}

Pengamatan iklim mikro dilakukan pada 1 bulan setelah tanam sampai pada akhir masa vegetatif. Hal ini didasarkan bahwa pada awal pertanaman kondisi iklim mikro disekitar tanaman masih relatif sama karena daun masih kecil dan belum menaungi secara berarti.

\section{Suhu Pertanaman}

Suhu pertanaman diamati pada bagian atas, tengah, dan bawah. Hal ini dilakukan untuk melihat ada atau tidaknnya perbedaan pengaruh sistem tanam pada bagian atas, tengah, dan bawah. Dari hasil analisis sidik ragam terhadap parameter suhu terdapat karakteristik yang menarik dimana pada umur 4 MST pada bagian atas pertanaman terdapat perbedaan suhu yang nyata pada sistem tanam Sigle Row dibandingkan dengan suhu sistem tanam Doble Row, Twins Row dan Twins Seed, sedangkan pada bagian bawah dan tengah pertanaman kondisi suhu tidak berbeda nyata (Tabel 1). Hal sebaliknya terjadi pada umur 9 MST dimana terdapat perbedaan yang nyata suhu pada bagian bawah pertanaman dimana suhu pada sistem tanam sigle row berbeda nyata dibandingkan pada sistem tanam yang lain. Sedangkan pada bagian tengah dan atas tidak terjadi perbedaan nyata suhu pada semua perlakuan. Hal ini diduga diakibatkan oleh tahapan pertumbuhan tanaman jagung, dimana pada saat 4 minggu setelah tanam memasuki vase V5 dan pada 9 minggu setelah tanam memasuki fase Vn (berbunga jantan).

Tabel 1. Hasil Sidik Ragam Parameter suhu

\begin{tabular}{|c|c|c|c|c|c|c|c|c|c|}
\hline \multirow[t]{3}{*}{ Perlakuan } & \multicolumn{9}{|c|}{ Suhu $\left({ }^{\circ} \mathrm{C}\right)$} \\
\hline & \multicolumn{3}{|c|}{4 MST } & \multicolumn{3}{|c|}{6 MST } & \multicolumn{3}{|c|}{9 MST } \\
\hline & Bawah & Tengah & Atas & Bawah & Tengah & Atas & Bawah & Tengah & Atas \\
\hline Sigle Row & $28.5 a$ & $29.4 a$ & $30.2 \mathrm{a}$ & $29.5 a$ & $29.4 a$ & $29.0 \mathrm{a}$ & $28.6 a$ & $28.3 a$ & $29.0 \mathrm{a}$ \\
\hline Doble Row & $28.3 a$ & $28.7 \mathrm{a}$ & $29.3 b$ & $28.4 \mathrm{a}$ & $28.7 \mathrm{a}$ & $28.9 a$ & $27.9 \mathrm{~b}$ & $27.8 \mathrm{a}$ & $28.9 \mathrm{a}$ \\
\hline Twins Row & $28.2 \mathrm{a}$ & $28.9 a$ & $29.3 b$ & $29.7 \mathrm{a}$ & $28.9 \mathrm{a}$ & $29.2 \mathrm{a}$ & $28.2 b$ & $28.1 \mathrm{a}$ & $29.2 \mathrm{a}$ \\
\hline Twins Seed & $28.5 \mathrm{a}$ & $29.2 \mathrm{a}$ & $30.1 \mathrm{~b}$ & $29.6 a$ & $29.2 \mathrm{a}$ & $29.2 \mathrm{a}$ & $28.2 b$ & $28.1 \mathrm{a}$ & $29.2 \mathrm{a}$ \\
\hline Respon & tn & tn & * & tn & tn & tn & * & tn & tn \\
\hline
\end{tabular}

Keterangan $: \mathrm{tn}=$ tidak nyata, $*=$ nyata pada taraf $5 \%$. Angka yang diikuti huruf sama tidak menunjukkan perbedaan nyata pada taraf uji BNT $5 \%$

Pada fase pertumbuhan V5 yaitu pada umur 18 - 35 hari setelah berkecambah, dimana pertumbuhan daun sangat pesat. Fase pertumbuhan VT yaitu pada saat berbunga dimana jumlah daun terbuka sempurna (Subekti N.A. dkk, 2011).

Pada fase V5 titik tumbuh daun diatas pada sigle row lebih tidak rapat dibandingkan pada perlakuan lain, yang mengakibatkan suhu diatas lebih tinggi. Sedangkan daun pada bagian tengah tidak ada perbedaan kerapatan sehingga kondisi suhu tidak berbeda nyata

Hal yang sama terjadi pada 9 MST dimana tanaman masuk fase VT saat berbunga jantan dimana daun sudah terbuka sempuna. Pada bagian atas dan tengah daun terbuka sempurna akan tetapi pada bagian bawah daun kecil dan sebagian mati sehingga suhu yang tercipta disebabkan oleh kerapatan populasi. Semakin rapat populasi maka energi matahari yang masuk akan rendah yang menyebabkan suhu menjadi rendah, dalam hal ini sigle row memiliki jarak antar tanaman yang longer sehingga memungkinkan terjadinya energi matahari yang lebih tinggi masuk kebagian bawah tanam sehingga menyebabkan suhu lebih tinggi. 


\section{Kelembaban Relatif (\%)}

Semua perlakuan tidak memberikan respon nyata pada kelembaban relatif di bawah, tengah dan atas pertanaman, baik pada 4 MST, 6 MST, dan 9 MST (Tabel 2). Hal ini diduga bahwa suhu yang diakibatkan oleh perlakuan tidak menyebabkan perbedaan kemampuan mengandung uap air di udara sehingga kelembaban relatif pada semua perlakuan sama. Jumlah uap air yang dapat dikandung udara ditentukan oleh suhu udaranya. Semakin tinggi suhu udara maka potensi mengandung uap air semakin meningkat (Handoko. 1995).

Tabel 2. Hasil Sidik Ragam Parameter suhu

\begin{tabular}{|c|c|c|c|c|c|c|c|c|c|}
\hline \multirow[t]{3}{*}{ Perlakuan } & \multicolumn{9}{|c|}{ Kelembaban Relatif (\%) } \\
\hline & \multicolumn{3}{|l|}{4 MST } & \multicolumn{3}{|c|}{6 MST } & \multicolumn{3}{|l|}{9 MST } \\
\hline & Bawah & Tengah & Atas & Bawah & Tengah & Atas & Bawah & Tengah & Atas \\
\hline Sigle Row & $81.5 \mathrm{a}$ & $75.8 \mathrm{a}$ & $77.3 \mathrm{a}$ & $74.9 \mathrm{a}$ & $69.0 \mathrm{a}$ & $72.6 \mathrm{a}$ & $87.2 \mathrm{a}$ & $82.8 \mathrm{a}$ & $85.5 \mathrm{a}$ \\
\hline Doble Row & $79.1 \mathrm{a}$ & $73.4 \mathrm{a}$ & $76.7 \mathrm{a}$ & $76.9 \mathrm{a}$ & $68.3 \mathrm{a}$ & $73.5 \mathrm{a}$ & $88.2 \mathrm{a}$ & $84.8 \mathrm{a}$ & $85.5 \mathrm{a}$ \\
\hline Twins Row & $76.3 \mathrm{a}$ & $72.5 \mathrm{a}$ & $72.7 \mathrm{a}$ & $73.1 \mathrm{a}$ & $69.2 \mathrm{a}$ & $73.5 \mathrm{a}$ & $87.2 \mathrm{a}$ & $85.0 \mathrm{a}$ & $85.3 \mathrm{a}$ \\
\hline Twins Seed & $80.3 \mathrm{a}$ & $80.2 \mathrm{a}$ & $76.4 \mathrm{a}$ & $74.9 \mathrm{a}$ & $68.2 \mathrm{a}$ & $71.7 \mathrm{a}$ & $87.3 \mathrm{a}$ & $84.4 \mathrm{a}$ & $85.8 \mathrm{a}$ \\
\hline Respon & $\operatorname{tn}$ & tn & $\operatorname{tn}$ & tn & $\operatorname{tn}$ & $\operatorname{tn}$ & tn & th & $\operatorname{tn}$ \\
\hline
\end{tabular}

Keterangan $:$ tn $=$ tidak nyata, $*$ = nyata pada taraf $5 \%$. Angka yang diikuti huruf sama tidak menunjukkan perbedaan nyata pada taraf uji BNT $5 \%$

\section{Intersepsi Cahaya (\%)}

Hasil sidik ragam munjukkan bahwa intersepsi Cahaya (\%) terjadi perbedaan respon nyata pada siang hari saat tanaman berusia 4 minggu setelah tanam dan Sore hari pada saat tanaman berusia 9 mst (Tabel 3). Pada saat tanaman jagung berumur 4 minggu setelah tanam perlakuan Twins Seeds memiliki intersepsi cahaya berbeda nyata dibanding perlakuan lain hal ini diduga jarak tanam Twins Seed $40 \mathrm{~cm}$ x $75 \mathrm{~cm}$ masih memberikan jarak tanpa naungan lebih tinggi dibandingkan dengan Doble row $(20 \mathrm{cmx} 20 \mathrm{~cm} x 80 \mathrm{~cm})$, Twins Row $(20 \mathrm{~cm} \times 10 \mathrm{~cm} \times 80 \mathrm{~cm})$, dan Sigle Row $(75 \mathrm{~cm} \times 20 \mathrm{~cm})$, sehingga sinar matahari lebih banyak masuk kepertanaman tanpa ada halangan dari daun. Sedangan pada 9 mst perlakuan sigle row memiliki Intersepsi Cahaya tertinggi pada sore hari ini diduga karena faktor kerapatan naungan daun yang diakibatkan jarak tanam yang digunakan. Jarak tanam Sigle Row memiliki tingkat kerapan rendah sehingga cahaya lebih banyak masuk melalui sisi barisan.

Tabel 3. Hasil Sidik Ragam Intersepsi Cahaya (\%)

\begin{tabular}{|c|c|c|c|c|c|c|c|c|c|}
\hline \multirow[t]{3}{*}{ Perlakuan } & \multicolumn{9}{|c|}{ Intersepsi Cahaya $(\%)$} \\
\hline & \multicolumn{3}{|l|}{4 MST } & \multicolumn{3}{|c|}{6 MST } & \multicolumn{3}{|c|}{9 MST } \\
\hline & Pagi & Siang & Sore & Pagi & Siang & Sore & Pagi & Siang & Sore \\
\hline Sigle Row & $22.2 \mathrm{a}$ & $25.0 \mathrm{a}$ & $18.0 \mathrm{a}$ & $13.3 \mathrm{a}$ & $26.0 \mathrm{a}$ & $19.0 \mathrm{a}$ & $13.3 \mathrm{a}$ & $24.0 \mathrm{a}$ & $18.7 \mathrm{a}$ \\
\hline Doble Row & $16.0 \mathrm{a}$ & $19.8 \mathrm{a}$ & $13.5 \mathrm{a}$ & $13.9 \mathrm{a}$ & $24.3 \mathrm{a}$ & $16.3 \mathrm{a}$ & $12.8 \mathrm{a}$ & $22.0 \mathrm{a}$ & $13.7 \mathrm{~b}$ \\
\hline Twins Row & $22.8 \mathrm{a}$ & $19.3 \mathrm{a}$ & $16.4 \mathrm{a}$ & $15.1 \mathrm{a}$ & $15.0 \mathrm{a}$ & $17.31 \mathrm{a}$ & $14.7 \mathrm{a}$ & $23.0 \mathrm{a}$ & $16.3 \mathrm{ab}$ \\
\hline Twins Seed & $21.3 \mathrm{a}$ & $31.1 b$ & $18.3 \mathrm{a}$ & $14.0 \mathrm{a}$ & $17.7 \mathrm{a}$ & $30.7 \mathrm{a}$ & $12.8 \mathrm{a}$ & $23.3 \mathrm{a}$ & $15.0 \mathrm{ab}$ \\
\hline Respon & $\operatorname{tn}$ & $*$ & tn & tn & tn & tn & tn & tn & $*$ \\
\hline
\end{tabular}

Keterangan $:$ tn $=$ tidak nyata, $*$ = nyata pada taraf $5 \%$. Angka yang diikuti huruf sama tidak menunjukkan perbedaan nyata pada taraf uji BNT $5 \%$

\section{Parameter Produksi}

Hasil sidik ragam parameter produksi menunjukkan tidak terdapat respon nyata terhadap diameter tongkol (mm), panjang tonggkol (mm) dan bobot tongkol (gram) (Tabel 4). Sehingga pola tanam doble row, twins row dan twins seed bisa dijadikan alternatif pola tanam yang dapat dilakukan untuk meningkatkan produksi persatuan luas luas mengingat pola tanam tersebut memiliki jumlah populasi yang lebih besar kecuali pada pola tanam twins row. Pola tanam twins row memiliki jumlah populasi yang sama dengan pola tanam sigle row, akan tetapi pola tanam ini berpotensi sebagai alternative pola tanam jagung untuk tumpang sari, dimana pada sistem tersebut biasanya dilakukan pelebaran antar baris sehingga akan kekurangan jumlah 
tanaman jagung. Penanaman 2 lubang per baris diharapkan akan mendapatkan jumlah populasi lebih besar sehingga hasil jagung bisa mendekati hasil jagung yang budidayanya monokulture dengan pola tanam sigle row.

Tabel 4. Hasil Sidik Ragam Parameter Produksi

\begin{tabular}{lccc}
\hline Perlakuan & \multicolumn{3}{c}{ Parameter } \\
\cline { 2 - 4 } & $\begin{array}{l}\text { Dameter tongkol } \\
(\mathrm{mm})\end{array}$ & $\begin{array}{l}\text { Panjang Tongkol } \\
(\mathrm{cm})\end{array}$ & $\begin{array}{l}\text { Bobot tongkol } \\
(\mathrm{gram})\end{array}$ \\
\hline Sigle Row & $55.1 \mathrm{a}$ & $20.1 \mathrm{a}$ & $354.8 \mathrm{a}$ \\
Doble Row & $54.8 \mathrm{a}$ & $18.9 \mathrm{a}$ & $316.5 \mathrm{a}$ \\
Twins Row & $54.9 \mathrm{a}$ & $18.8 \mathrm{a}$ & $328.5 \mathrm{a}$ \\
Twins Seed & $55.3 \mathrm{a}$ & $18.8 \mathrm{a}$ & $325.4 \mathrm{a}$ \\
\hline Respon & $\mathrm{tn}$ & $\mathrm{tn}$ & $\mathrm{tn}$
\end{tabular}

Keterangan : tn $=$ tidak nyata, $*=$ nyata pada taraf $5 \%$, Angka yang diikuti huruf

sama tidak menunjukkan perbedaan nyata pada taraf uji BNT $5 \%$

Bila dibandingkan dengan diskripsi varietas jagung manis bonanza memiliki bobot $270-300$ gram (Panah Merah, 2009). Oleh karena itu walaupun dengan menggunakan jarak tanam rapat dan populasi lebih tinggi jagung manis yang dihasilkan memiliki bobot diatas potensi hasilnya (Tabel 4).

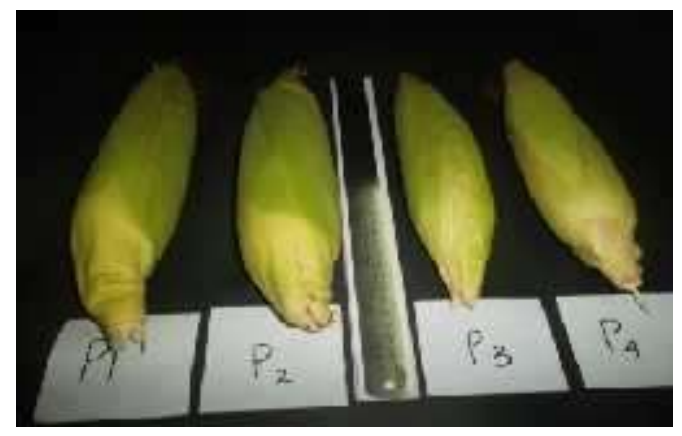

Gambar 1. Hasil Jagung Manis perlakuan P1= Sigle Row, P2=Doble Row, P3= Twins Row dan P4= Twins Sed

Bobot tongkol pada sistem tanam doble row, twins row, dan twins seed yang memiliki populasi tinggi akan tetapi masih memiliki bobot pada kisaran diskripsi varietasnya diduga disebabkan oleh jarak tanam yang digunakan belum menyebabkan kompetisi antar tanaman yang sampai mempengaruhi hasil tanaman. Hal ini juga diduga bahwa masing masing tanaman dapat melakukan penyesuaian dan keseimbangan terhadap keterbatasan sumberdaya yang diakibatkan kepadatan populasi. Kompetisi tanaman terjadi bila dua individu atau lebih hidup bersama dan membutuhkan sumberdaya yang sama dalam keadaan terbatas, dimana derajat kompetisi dipengaruhi oleh jenis, kepadatan, pola pertumbuhan dan umur (Sastroutomo S.S, 1990). Kompetisi antar jenis tanaman yang sama melibatkan ruang, sinar matahari, bahan buangan, susceptibilitas terhadap pemangsa, penyakit, dan sebagainya. Akibat dari persaingan antar jenis dapat terjadinya penyesuaian keseimbangan dua jenis tanaman, salah satunya dengan menempati relung ekologi yang agak berbeda (Odum, E, 1996).

\section{KESIMPULAN}

Karakteristik iklim mikro sistem tanam jagung manis pada penelitian ini adalah : (a) Suhu $\left({ }^{\circ} \mathrm{C}\right)$, Terdapat perbedaan nyata pada suhu bagian atas tanaman saat 4 mst dan pada 9 mst terdapat perbedaan nyata 
pada suhu bagian bawah, dimana sigle row memiliki suhu yang berbeda dengan pelakuan lain (b). Semua sistem tanam memiliki kelembaban relative (\%) yang tidak berbeda nyata dan (c) Intersepsi Cahaya (\%) terdapat perbedaan nyata intersepsi cahaya siang hari pada saat $4 \mathrm{mst}$, dimana twins seed memiliki intersepsi cahaya yang berbeda dengan perlakuan lain dan terdapat perbedaan nyata intersepsi cahaya pada saat 9 mst dimana sigle row memiliki intersepsi cahaya yang berbeda dengan perlakuan lain. Produksi jagung manis pada perlakuan SR, DR, TR dan TS tidak berberda nyata dan memiliki bobot tongkol ( $\mathrm{SR}=354.8$ gram, $\mathrm{DR}=316.5$ gram, TR 328.5 gram dan $\mathrm{TS}=325.4$ gram) sama dengan diskripsi varietas bonanza (300-400 gram).

\section{DAFTAR PUSTAKA.}

Balitseral litbang deptan, 2013. Sistem Legowo Tanaman Jagung. Balai Serealia Litbang Pertanian. Kementrian Pertanian Republik Indonesia. http://balitsereal.litbang.deptan.go.id. Diakses 24 November 2013.

Handoko. 1995. Klimatologi Dasar. Pustaka Jaya. Jakarta

Panah Merah, 2009. Bonanza F1. http://www.panahmerah.id/home. Diakses 10 Oktober 2015

Rizka N.S. dkk. 2013.Perbandingan Pertumbuhan dan Produksi Jagung (Zea mays saccharata L) Sistem Tanam Satu Baris dan Dua Baris. Jurnal Agroteknologi. Volume 7 nomor 2. September 2011. ISSN 19795777

Rukmana R, 1997. Usaha Tani Jagung.Kanisiun. Yokyakarta.

Subekti N.A. dkk, 2011. Fase Perkecambahan dan Pertumbuhan Jagung Manis. Balai Penelitian Serealia, Maros. http//Jagung Bisi.com//Fase-perkecambahan-dan-pertumbuhan-tanaman-jagung/. Diakses. 10 oktober 2015 